University of Nebraska - Lincoln

DigitalCommons@University of Nebraska - Lincoln

\title{
Permethrin-Impregnated Yarn: Longevity of Efficacy and Potential Use on Cylindrical Fiberglass Stable Fly (Diptera: Muscidae) Traps
}

Jerome Hogsette

USDA-ARS, Jerry.Hogsette@ars.usda.gov

Joseph Ruff

USDA-ARS

Follow this and additional works at: https://digitalcommons.unl.edu/usdaarsfacpub

Part of the Agricultural Science Commons

Hogsette, Jerome and Ruff, Joseph, "Permethrin-Impregnated Yarn: Longevity of Efficacy and Potential Use on Cylindrical Fiberglass Stable Fly (Diptera: Muscidae) Traps" (1996). Publications from USDA-ARS / UNL Faculty. 1010.

https://digitalcommons.unl.edu/usdaarsfacpub/1010

This Article is brought to you for free and open access by the U.S. Department of Agriculture: Agricultural Research Service, Lincoln, Nebraska at DigitalCommons@University of Nebraska - Lincoln. It has been accepted for inclusion in Publications from USDA-ARS / UNL Faculty by an authorized administrator of DigitalCommons@University of Nebraska - Lincoln. 


\title{
Permethrin-Impregnated Yarn: Longevity of Efficacy and Potential Use on Cylindrical Fiberglass Stable Fly (Diptera: Muscidae) Traps
}

\author{
JEROME A. HOGSETTE AND JOSEPH P. RUFF ${ }^{1}$ \\ Center for Medical, Agricultural, and Veterinary Entomology, USDA-ARS,
} P.O. Box 14565, Gainesville, FL 32604

\begin{abstract}
J. Econ. Entomol. 89(6); 1521-1525 (1996)
ABSTRACT Efficacy of permethrin-impregnated orlon yam against stable flies, Stomoxys calcitrans (L.), was 6-8 wk under simulated field conditions. Numbers of stable flies captured on corrugated cylindrical fiberglass traps painted with an adhesive indicated that these traps are attractive enough to be used in the field with treated yarn applied. Reasons for variability of yarn impregnation and the use of yarn on cylinder traps are discussed.
\end{abstract}

KEY WORDS Stomoxys calcitrans, Williams traps, toxicant devices, cylinder traps, stable fly control

ADHESIVE-COATED FIBERGLASS TRAPS have become commonplace for sampling populations of adult stable flies, Stomoxys calcitrans (L.). The cross-configuration trap of flat alsynite fiberglass panels, first devised by Williams (1973), has been replaced largely by a cylindrical fiberglass trap (Broce 1988). Although sticky traps have been used primarily for research purposes, a corrugated version of the cylindrical trap is being sold commercially (Hogsette and Ruff 1990).

Sticky traps have been used to reduce stable fly populations (Rugg 1982), but trapped flies and wind-blown debris (dust and so on) obscure trap surfaces, causing a decrease in attractiveness as the flies accumulate (Agee and Patterson 1983). Therefore, a high degree of trap maintenance is necessary, particularly when fy populations are large or traps are placed in dusty habitats such as feedlots. By coating trap surfaces with a pesticide in lieu of an adhesive, the fly trap becomes a toxicant device that is very effective for controlling stable flies. Unfortunately, pesticide formulations do not adhere well to the fiberglass surface and can be washed off by heavy dew or light rain (Meifert et al. 1978).

Application of pesticide-impregnated yarn to fiberglass panels without adhesive has been investigated, but the initial crisscross yarn application method is cumbersome to use (Koehler and Patterson 1982). A single-strand yarn application method that is easier to use was subsequently de-

\footnotetext{
This article reports the results of research only. Mention of a proprietary product or a pesticide does not constitute an endorsement or a recommendation for its use by USDA.

'Dog Fly Control, Florida Department of Agriculture and Consumer Services, Panima City, FL. 32405.
}

veloped, and the most advantageous yarn-spacing interval was determined (Tseng et al. 1986). Although preliminary field test results indicated that pesticide-impregnated yarn would remain effective on fiberglass panels for up to 4 mo (Hogsette et al. 1987), additional testing was needed to substantiate these findings.

It is possible that impregnated yarn might be applied to commercial fiberglass cylinder traps because of their availability. However, the reaction of stable flies to the fiberglass used for the commercial cylinder trap is not reported in the literature. Unlike the original fiberglass cylinder trap (Broce 1988), the commercial trap is made of corrugated fiberglass and, in practice, the trap surface is always covered with an adhesive-coated, clear-plastic sleeve (Hogsette and Ruff 1990). Stable fly distribution patterns have been investigated on cylinder traps made from flat fiberglass (Broce et al. 1991), but not on those made from corrugated fiberglass.

One objective of this study was to test the longevity of yarn impregnated with permethrin using the method of Koehler and Patterson (1982) and placed on fiberglass panels under field and simmlated field conditions. Flat alsynite panels instead of cylinder traps were used for these tests because the flat surface made it easy to expose small cages of flies to the impregnated yarn. Because the efficacy of sticky traps (Rugg 1982) and toxicant devices (Meifert et al. 1978) for stable fly control has been documented fully in field trials, we saw no reason to perform similar trials with yarn-wrapped traps.

A second objective was to test the commercial cylinder trap surface-coated with an adhesive to determine how stable flies respond to this device 


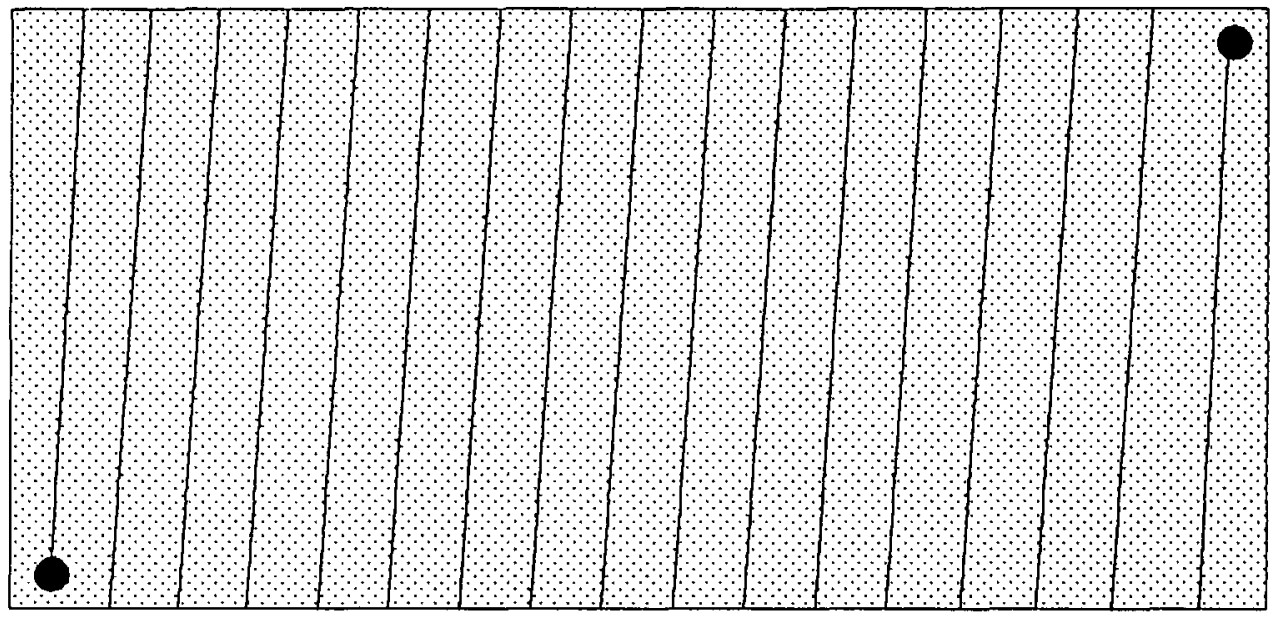

Fig. 1. Diagram of individual fiberglass panel showing holes at diagonally opposite corners and continuous coil yarn application (not to scale).

without its usual covering of an adhesive-coated plastic sleeve. Also, efficacy of cylinder traps surface-coated with adhesive were compared with those wrapped with adhesive-coated clear plastic sleeves.

\section{Materials and Methods}

Yarn Longevity Tests. Flat, clear alsynite panels ( 28 by $43 \mathrm{~cm}, 600$ series, $1.14 \mathrm{~mm}$ [ 45 mil], International Enterprises, Atlanta, GA) were used for all tests with insecticide-impregnated yarn. The $43-\mathrm{cm}$ sides of each panel were notched at $1.3-\mathrm{cm}$ intervals, the optimum spacing found by Tseng et al. (1986), and small holes were made in 1 pair of diagonally opposite corners (Fig. 1). A $15-\mathrm{cm}$ slit (for joining one panel to another) was made in each panel parallel to the $28-\mathrm{cm}$ side at the midpoint of the $43-\mathrm{cm}$ side.

For simulated field tests (tests 1-4), yarnwrapped panels were joined at the slits at $90^{\circ}$ angles to form Williams traps (Williams 1973) and placed in vertical cuts (14-cm long) made in wooden stakes $(5$ by $5-\mathrm{cm})$. The bottom margins of the traps were $\approx 90 \mathrm{~cm}$ above ground level. Stakes had wooden supports near the bottom so they could be placed on concrete surfaces.

When Williams traps were mounted on wooden stakes, the stakes divided the fiberglass panels into 4 wings ( $\approx 20$ by $28 \mathrm{~cm}$ each). Before yarn was applied, a pair of holes $11 \mathrm{~cm}$ apart was made near the center of each wing. After yarn was applied, the ends of a nubber band (or $\geq 2$ rubber bands joined together) were passed through each pair of holes and secured with small dowels. This provided loops of rubber on 1 side of the panels for attaching exposure cages.

Permethrin was used for tests 1 and 2 (Ectiban EC, $5.7 \%$ [AI], ICI Americas, Wilmington, DE) and for test 3 (Overkill 5.7 EC, 5.7\% [AI], Farnam Companies, Omaha, NE).

White $100 \%$ orlon yarn was impregnated by $\mathrm{im-}$ mersing it for $20-30 \mathrm{~min}$ in a $1 \%$ aqueous solution of permethrin EC maintained at $66^{\circ} \mathrm{C}$ (Koehler and Patterson 1982). Yarn was removed from the permethrin solution, suspended above a shallow pan, and allowed to air-dry for 3-4 d in the laboratory. Yarn was applied to panels by tying the loose end of the yarn through the hole in one corner, placing yarn in the notches as it was wrapped in a continuous coil around the long axis of the panel, and tying yarn through the hole in the diagonally opposite corner (Fig. 1).

Yarn for tests 1 and 2 was treated on the same day. Before it was used, yarn impregnated for test 2 was aged for $\approx 12 \mathrm{mo}$ in the laboratory in plastic bags under indirect light. Yarn for test 3 was impregnated and used immediately after drying.

Exposure cages were fabricated from $240-\mathrm{ml}$ (10 $\mathrm{cm}$ high) clear plastic specimen cups by removing the bottoms and replacing them with disks of standard aluminum window screen. Exposure cages have flat paper lids that can be taken off and replaced as cages are being placed on and removed from the trap surface without contaminating the inside of the cages and without releasing the flies contained within. Adult stable flies $(3-5$ d old, mixed sex) from the USDA Gainesville colony (Hogsette 1992) were used for all tests. Flies were anesthetized with carbon dioxide, placed in exposure cages, and allowed to recover for $\geq 30 \mathrm{~min}$ before each test.

Yarn efficacy was evaluated weekly by placing 1 exposure cage containing 25 stable flies on each panel for $15 \mathrm{~min}$. At the beginning of each $15-\mathrm{min}$ exposure period, 1 exposure cage of 25 stable flies was placed on the ground below each panel or trap as a control. Cages on panels were tapped lightly 
Table 1. Experimental design for longevity tests under simulated field conditions of impregnated yarn applied to Williams traps

\begin{tabular}{ccccc}
\hline \hline Test & No. traps & $\begin{array}{c}\text { No. cages } \\
\text { per trap }\end{array}$ & Florida location & Test dates \\
\hline 1 & 4 & 2 & USDA laboratory & 18 Aug.-28 Oct. 1993 \\
& 4 & 2 & 11 Nov. 1993-25 Jan. 1994 \\
$2^{a}$ & 3 & 2 & Univ. Florida campus & 10 June-2 Sept. 1994 \\
3 & 4 23 Jan. -4 April 1995 \\
\hline
\end{tabular}

a Yarn aged 12 mo.

to ensure contact between flies and yarn. After each exposure period, all flies were returned to the laboratory and provided with a $10 \%$ sucrose solution through the screened portion of the exposure cuges. Mortality counts were made after $24 \mathrm{~h}$. The criterion for death was complete cessation of movement.

For tests 1 and 3, traps were placed on a concrete surface outside the USDA laboratory where they were exposed to ambient atmospheric conditions for the duration of each test. Testing began within $24 \mathrm{~h}$ (test 1) or $1 \mathrm{wk}$ (test 3) after outside placement. For test 2, traps were placed on a fenced concrete surface outside a large cattle barn on the University of Florida campus. Testing began 2 wk after placement. An experimental design for all tests is shown in Table 1.

Tests with Cylinder Traps. Commercial cylinder traps (Olson Products, Medina, $\mathrm{OH}$ ) were formed from single rectangular pieces of corrugated clear fiberglass $(0.89 \mathrm{~mm}$ [35 mil]) held together top and bottom with large metal paper clips. Traps $(30 \mathrm{~cm}$ high, $20 \mathrm{~cm}$ diameter) were placed on wooden stakes in vertical slits cut half as long as the trap height. Stakes, placed $15 \mathrm{~m}$ apart along a fence line, held bottom margins of the traps $\approx 90$ $\mathrm{cm}$ above ground level. The trapping site was close to confined sheep where stable fly adults were observed.

Table 2. Percentage mortality of stable fly adults exposed to permethrin-impregnated yarn applied to Williams traps

\begin{tabular}{cccc}
\hline Week & $\begin{array}{r}\text { Test 1 } \\
(n=8)\end{array}$ & $\begin{array}{c}\text { Test 2a } \\
(n=8)\end{array}$ & $\begin{array}{c}\text { Test 3 } \\
(n=6)\end{array}$ \\
\hline 0 & 100.00 & - & - \\
1 & 99.68 & - & 34.78 \\
2 & 98.20 & 100.00 & 100.00 \\
3 & 96.02 & 93.47 & 100.00 \\
4 & 100.00 & 63.09 & 100.00 \\
5 & 98.87 & 95.62 & 99.33 \\
6 & 93.65 & $100.00^{b}$ & 100.00 \\
7 & 97.13 & $18.42^{b}$ & 100.00 \\
8 & 85.71 & 41.47 & 73.33 \\
9 & 65.74 & 41.47 & 68.00 \\
10 & 72.50 & 26.63 & 20.00 \\
11 & 86.39 & 82.49 & 4.67 \\
12 & 46.69 & 25.57 & - \\
\hline
\end{tabular}

A replicate was 1 cage of 25 stable fly adults.

"Yam impregnated and stored $\approx 12$ mo before use.

b Rain during test.
To observe the stable fly response to comgated alsynite, surfaces of 4 cylinder traps were coated with Sticky Stuff adhesive (Olson) and a fly count was made $24 \mathrm{~h}$ later. When flies were counted, it was noted whether they were on the top or bottom half of the traps and whether they were on the peaks or in the valleys of the corrugated fiberglass. Tests were replicated 8 times.

Cylinder traps coated with Sticky Stuff were compared with those wrapped with clear Sticky Sleeves (Olson). The 2 trap types were placed alternately on stakes as described above; flies were counted after $24 \mathrm{~h}$ and trap positions were reversed. Tests consisting of 2 traps with each sticky material were replicated 8 times.

Statistical Procedures. Means of impregnated yarn mortality data were calculated for test $1(n=$ 8,2 consecutive tests, but data were pooled), test $2(n=8)$, and test $3(n=6)$. Although actual values are shown in tables and text, percentage mortality values were subjected to arcsine transformation before calculations were made. Cylinder trap capture pattern data in a $2 \times 2$ factorial design (effects of trap position were not analyzed) were analyzed with GLM procedures, and the Student $t$-test (SAS Institute 1985) was used for separation of means. Unless otherwise stated, $P=0.05$.

\section{Results and Discussion}

Yarn Longevity Tests. Activity of permethrinimpregnated yarn in simulated field tests was variable, particularly after week 8 (Table 2). Mortality for test 1 remained $\geq 90 \%$ until week 8 when it began to decline; it resurged to $86 \%$ on week 11 and then dropped sharply. In contrast, mortality for test 2 (aged yarn) decreased to $63 \%$ by week 4 , increased to $100 \%$ by week 6 , then dropped sharply before and after increasing to $83 \%$ on week 11 (Table 2). Control mortality was $<10 \%$ with the exception of test 3 , week 1 .

Results of tests 1 and 3 were similar to those of previous field tests where mortality dropped below $90 \%$ after 8 wk on an extremely dusty dairy (J.A.H. and J.P.R., unpublished data). Dust accumulation on the fiberglass or the yarn was not evident during any tests, previous or current, but variable mortality data suggest that the yarn surface may have been partially occluded. 
Contrary to what has been stated previously (Hogsette et al. 1987, Foil and Hogsette 1994), yarn impregnated using the method of Koehler and Patterson (1982) should not be left in the field for longer than $8 \mathrm{wk}$. Longevity of yam efficacy was not affected by age of the permethrin; however, we recommend that fresh stocks of permethrin be used for impregnation of yarn.

Results of test 2, performed in a dusty location with treated yarn that had been stored for $12 \mathrm{mo}$, were quite variable (Table 2). Apparently, the effects of storage time and dust accumulation affected the activity of the treated yarn. Under general field conditions with moderate amounts of dust, yarn should be used as soon as possible after impregnation.

Rainfall occurred during weeks 6 and 7 of test 2 when flies were exposed to the yarn (Table 2). We thought perhaps the rain would remove accumulated dust from the yarn and increase its effectiveness. However, this did not occur, and results during the remainder of test 2 continued to be erratic.

Potential factors affecting percentage mortality data include variability of yarn impregnation. Although impregnation instructions were followed carefully, the process may have been affected by slight changes in impregnation temperature or time. We assumed that the permethrin was impregnated uniformly into the yarn, but this was not verified by chemical analysis. If results were negatively affected by meteorological factors such as ultraviolet light, rain, or ambient temperature, or physical factors such as accumulation of dust on yarn, we would expect these effects to be expressed in a similar manner during each test.

Tests with Cylinder Traps. Significant differences $(F=27.11 ; \mathrm{df}=8,63 ; P=0.0001)$ existed in stable fly capture patterns on corrugated cylinder traps. Numbers of flies captured on the bottom halves of the traps (mean $=18$ ) were significantly greater than those captured on the top halves (mean $=11.2$ ). These data compare favorably with those of Broce et al. (1991) who found that most stable flies were captured on the bottom halves of their cylinder traps made from flat fiberglass. The attraction of stable flies to the bottom portion of an elevated fiberglass cylinder may partially explain the success of the cylinder trap devised by Gersabeck et al. (1982). Gersabeck et al. (1982), who were not concerned with capturing flies on the trap surface, also worked with flat alsynite, possibly because attractiveness of flat alsynite was reported at that time to be superior to that of corrugated alsynite (Ruff 1979).

Numbers of flies captured on the peaks of the corrugated fiberglass (mean $=18.4$ ) were significantly greater than those captured in the valleys (mean $=10.8$ ). This was not surprising because stable flies do not usually alight on fiberglass sticky traps except at the top and bottom margins. Instead, flies tend to be captured on their lateral or dorsal aspects as they fly close to the traps and brush the surface (J.A.H., unpublished data).

This phenomenon changes when yarn is applied vertically to the fiberglass surface. Optimum yarn spacing tests were performed to determine how much yarn could be applied to alsynite panels without reducing their attractiveness (Tseng et al. 1986). By maximizing the amount of yarn applied to panels, we hoped that flies would inadvertently touch the yarn during their attempts to contact the fiberglass surface of the trap. However, during earlier field tests (Hogsette et al. 1987), stable flies actually landed on the vertically oriented strands of treated yarn. The attraction of stable flies to vertically oriented wires has since been substantiated (Pickens 1991).

Cylinder traps coated with Sticky Stuff captured nearly twice as many $(77.5 \pm 32.1$ ) (mean $\pm S E$ ) stable flies as cylinder traps wrapped with Sticky Sleeves $(39.0 \pm 23.3)$. Results demonstrated that the cylinder trap without the Sticky Sleeve was capable of attracting adequate numbers of stable flies. Therefore, this trap configuration would be suitable for use with permethrin-impregnated yarn.

Care must be taken to prevent stable flies from becoming resistant to pesticides impregnated into any materials exposed constantly to the environment. Pesticide resistance was detected recently in stable fly populations (Cilek and Greene 1994) and rapid development could occur through misuse of sustained release devices. If a sustained release toxicant system for stable flies is to be commercialized, more efficacious impregnation techniques should be used, and a visual system should be devised to inform the user when it is time to replace the impregnated material.

\section{Acknowledgments}

We thank A. Lee and G. Langley (USDA-ARS, Gainesville, FL) and C. F. Bass and S. W. Campbell (State of Florida, Department of Health and Rehabilitative Services) for their technical assistance in this study, and J. E. Cilek, G. T. Fincher, and C. J. Geden for their critical reviews of this article. Research was supported in part by Cooperative Agreement No. 58-7B30-0-190 between USDA and the State of Florida, Department of Health and Rehabilitative Services.

\section{References Cited}

Agee, H. R., and R. S. Patterson. 1983. The spectral sensitivity of stable, face, and horn flies and behavioral responses of stable flies to visual traps (Diptera: Muscidae). Environ. Entomol. 12: 1823-1828.

Broce, A. B. 1988. An improved alsynite trap for stable flies, Stomoxys calcitrans (Diptera: Muscidae). J. Med. Entomol. 25: 406-409.

Broce, A. B., J. R. Schwenke, and K. E. Hampton. 1991. Landing pattern of stable flies (Diptera: Muscidae) on the alsynite cylinder trap: effect of wind speed and direction. I. Med. Entomol. 28: 730-733. 
Cilek, J. E., and G. L. Greene. 1994. Stable fly (Diptera: Muscidae) insecticide resistance in Kansas cattle feedlots. J. Econ. Entomol. 87: 275-279.

Foil, L. D., and J. A. Hogsette. 1994. Biology and control of tabanids, stable flies and hom flies. Rev. Sci. Tech. O. I. E. (Off. Int. Epizoot.) 13: 1125-1158.

Gersabeck, E. F., R. W. Merritt, and J. D. Haefner. 1982. An efficient trap for collecting wild adult stable flies, Stomoxys calcitrans (Diptera: Muscidae), for mark-release studies. J. Med. Entomol. 19: 541-544.

Hogsette, J. A. 1992. New diets for production of house flies and stable fies (Diptera: Muscidae) in the laboratory. J. Econ. Entomol. 85: 2291-2294.

Hogsette, J. A., and J. P. Ruff. 1990. Comparative attraction of four different fiberglass traps to various age and sex classes of stable fly (Diptera: Muscidae) adults. J. Econ. Entomol. 83: 883-886.

Hogsette, J. A., J. P. Ruff, and C. J. Jones. 1987. Stable fly biology and control in northwest Florida. J. Agric. Entomol. 4: 1-11.

Koehler, P. G., and R. S. Patterson, 1982. Stable fly control with fiberglass panels. IFAS, University of Florida, Cooperative Extension Service Livestock Protection Pointer No. 14, Gainesville.
Meifert, D. W., R. S. Patterson, T. Whitfield, G. C. LaBrecque, and D. E. Weidhaas. 1978. A unique attractant-toxicant system to control stable fly popuations. J. Econ. Entomol. 71: 290-292.

Pickens, L. G. 1991. Battery-powered, electrocuting trap for stable Hies (Diptera: Muscidae). J. Med. Entomol. 28: 822-830.

Ruff, J. P. 1979. Trapping effectiveness of several combinations of colors and textures of sticky traps for stable flies, Stomoxys calcitrans (L.). Mosq. News 39: 290-292.

Rugg, D. 1982. Effectiveness of Williams traps in reducing the numbers of stable flies (Diptera: Muscidae). J. Econ, Entomol. 75: 857-859.

SAS Institute. 1985. SAS user's guide: statistics. SAS Institute, Cary, NC.

Tseng, J. M., J. A. Hogsette, and R. S. Patterson. 1986. Effect of yarn on attractiveness of the Wiliams trap to Stomoxys calcitrans (Diptera: Muscidae) adults. Fla. Entomol. 69: 261-263.

Williams, D. F. 1973. Sticky traps for sampling populations of Stomoxys calcitrans. J. Econ. Entomol. 66; 1279-1280.

Received for publication 22 November 1995; accepted 5 July 1996 . 